for five years to the radio education unit of the University College of the West Indies; $£ 20,000$ over three years on a tapering basis to the Government Central Pedalogical Institute, Allahabad, for teaching English; up to $£ 4,000$ to the University of Hong
Kong to enable Prof. J. E. Driver to purchase equipment for his Department of Chemistry, and $£ 3,600$ over three years to the Institute of Child Health, Calcutta, for studies of the pattern of disease in a sample group of children.

\title{
PROGRESS IN FOOD INVESTIGATION
}

$\mathrm{F}^{\mathrm{o}}$ OR many years the annual report published by the Department of Scientific and Industrial Research under the title "Food Investigation" has reviewed the work of the Food Investigation Board and of three research institutes, namely, the Low Temperature Research Station at Cambridge, the Ditton Laboratory, Maidstone (with its associated unit at Covent Garden), and the Torry Research Station, Aberdeen.

In 1958 the Council of the Department of Scientific and Industrial Research decided on a series of administrative changes: (1) to disband the Food Investigation Board; (2) to retain the Torry Station as an independent establishment of the Department; (3) to transfer the other two institutes to the Agricultural Research Council. This latter change was brought about "because the two Councils believe that it is in the national interest to bring all Government research on food, other than fish, under one organization, the aim being to make the research more effective". From now onwards a report on the Torry Research Station will be published annually by the Department of Scientific and Industrial Research; the report, "Food Investigation 1958"*, is limited to the Cambridge and Ditton Laboratories and will be the last to appear under the auspices of the Department.

The Cambridge and Ditton Laboratories are complementary to one another : at Ditton the emphasis is on problems associated with fruits and vegetables; at Cambridge, although important work is being carried out on plant tissues and products, the major stress has been on animal products-meat (including bacon and poultry), eggs and animal fats. At both centres there have been fundamental investigations in biochemistry, biophysics and microbiology, and the report illustrates how difficult it is (in any event in the field of food technology) to draw a distinction between pure and applied research; the examination of the factors governing the quality of meat, eggs or

" "Food Investigation 1958." Pp. vi+32. (London: H.M. Stationery Office, 1959.) 38 . fruit has stimulated basic work on the chemical composition of these materials and on the nature of the enzymes present ; in turn, the newer information obtained has helped in the solution of practical problems of food storage and preservation.

The Cambridge section of the report includes summaries of investigations on three recent developments in food technology, namely, the administration of cestrogenic hormones to young animals (to increase the rate of gain of weight and the efficiency of food conversion), the use of antibiotics in poultry storage and of radiations in meat preservation. Details are given also of recent research on the phenolic constituents of plants ; these compounds-ranging from relatively simple molecules to complex polymersare now known to play a significant part in the control of colour, flavour and texture in a wide variety of foods.

The Ditton Laboratory records the increased commercial use of the hydrocooling process for vegetables such as watercress and lettuce; controlled experiments have shown that vegetables subjected to this process should arrive fresher on the market and retain their quality for a longer period. Another important line of research is concerned with the storage of potatoes in bulk using a new method of suppressing sprout growth - the introduction of nonyl alcohol vapour into the ventilation system of the store. An account is given also of various lines of research in plant physiology and biochemistry, and in refrigeration and other aspects of 'biological engineering'.

The food industries in the United Kingdom owe a debt of gratitude to the Department of Scientific and Industrial Research for sponsorship of research over some decades; the annual reports of the Food Investigation Board and other publications from the individual laboratories have played an indispensable part both in stimulating industrial research and in placing food storage and processing in the United Kingdom on sound scientific foundations.

Francis Aylward

\section{THE HOVERCRAFT}

A DEVICE for forcing out compressed air between $A$ a ship's surface and the water was patented in 1883. It did not work. Many similar fruitless attempts were made in the next sixty years until, in 1953, Mr. C. S. Cockerell began experimenting with air lubrication. His success is now universally recognized and the first hovercraft has begun the hard task of practical development, foreshadowing a new contender in the field of maritime transport.

Cockerell began as had De Laval, by attempting to contain a sheet of air between the surface of a vessel, in this case a planing craft, and the sea. He found that the reduction in drag was offset by the hull modifications needed to supply the air. He then attempted to contain the air lubricating sheet between vertical plates but these plates increased the skin friction drag. The answer was to replace the solid containing plates by curtains of air and so the hovercraft was evolved.

The experimental version now flying, the 'SR-NI', is an oval dish on top of which are mounted the propulsion and control systems, and the air com. pressor. The compressor is a 7 -ft. diameter ducted fan powered by a 435-h.p. internal combustion aero engine. Two-thirds of the compressed air is fed to two concentric annular slots near the periphery of the 
under surface of the oval disk. The slots are shaped so that two continuous jet sheets are directed downwards and slightly inwards. When the engine is started the jets first build up the air cushion under the disk and then maintain the pressure difference between the cushion and the atmosphere. The pressure difference deflects the air curtains and they spill outwards at the ground or water surface (the pressure difference times the height above the ground must equal the radial rate of change of momentum). Two curtains are used for stability reasons. A third of the compressed air is bled off into two parallel propulsion ducts of rectangular crosssection which lie along and above the flat sides of the oval disk. Vanes at each end of each duct provide the necessary longitudinal and lateral control.

Because the weight that can be supported is dependent on the disk area while the power required is proportional to the peripheral length, the economy of a hovercraft should improve with size. A reasonably flat operational surface is required and early applications may well be over surfaces which existing vehicles find difficult, for example, marsh, snow, sand, ice and shallow rivers. Serious consideration has been given to a 400 -ton car ferry capable of carrying eight hundred passengers and eighty cars across the channel at a speed of 90 knots. A careful detailed study of hovercraft economics suggests a cost of between 8 and 18 pence per (payload) ton (nautical) mile in the speed-range $70-170$ knots. Both cost and speed lie somewhere between the current values for ships and commercial aircraft. If the hovercraft can prove its worth with modest payloads over short distances, then serious thought could be given to developing a trans-ocean hovercraft capable of crossing the Atlantic in $24 \mathrm{hr}$. This new competitor could not appear within the next ten years, however, and one wonders what the level of ship and particularly aircraft fares will be by then. Nevertheless, the hovercraft has an extremely interesting future and one can only congratulate the inventor and the development engineers on their achievement and remark that this is one enterprise where the Old World leads the New.

These remarks are based on a paper "The Hovercraft-a New Concept in Maritime Transport", by P. R. Crewe and W. J. Eggington, read before the Royal Institution of Naval Architects on November $19,1959$. J. L. STOLLERY

\section{NEW DELHI SYMPOSIUM ON ALGAE}

$\mathrm{P}$ OSSIBLY because algae are usually inconspicuous in the temperate regions in which most microbiologists receive their training, the dominant role which these organisms may have in soil and water in other climates is apt to be overlooked. In India, although much excellent work has been done on algae, this has largely followed morphological and systematic lines, and relatively little attention has been paid to their activities and possible economic importance. The symposium on "Allgology", held in the Indian Agricultural Research Institute, New Delhi, during December 7-11, under the auspices of Unesco and the Indian Council of Agricultural Research, had the object of stimulating investigations on the more practical aspects of the subject. It was opened by Mr. S. K. Patil, Minister for Food and Agriculture, and was attended by experts from Japan, England, the Federal Republic of Germany, and Israel, as well as by delegates from all parts of India.

An introductory address by Dr. M. S. Randhawa, chairman of the organizing committee, outlined the development of algal studies and lines of research which may be of practical importance. The principal uses to which these organisms may be put are mentioned below, but it may be noted that in the tropics algal growth often needs controlling rather than encouraging $\rightarrow$ a matter which was not considered in any of the papers which followed. The growth of blue-green algae, which generally occurs on buildings during wet weather, not only renders them unsightly but also corrodes the stone-work and presents a problem of major economic importance. Algal growth may also interfere in the manufacture of salt, it may block canals and irrigation channels, and pollute fresh water.

The papers presented covered nearly every aspect of modern knowledge of the algae. Classical morphology was represented by papers on the comparative morphology of the Charophytes, by V. S. Sundaralingam, and on reproduction in red algae, by $M$. S. Balakrishnan, and by a lecture by M. O. P. Iyengar, describing some of the many interesting species which have been discovered in India. Recent advances in the study of the submicroscopic morphology of algae were reviewed by T. V. Desikachary, who also discussed the structure of diatom frustules in the light of his own electron microscope investigations. Papers on algal cytology, which is especially important for the understanding of life-cycles and for taxonomy, were given by C. S. P. Rao, Y. S. R. K. Sarma and Y. B. K. Chowdary.

One of the most important of recent advances in algal physiology has been the introduction by $\mathbf{H}$. Tamiya and his associates of the technique of synchronous culture as a means of studying the metabolic changes occurring during the life-cycle. A paper by H. Tamiya summarized the main results obtained and dealt particularly with the role of sulphur in the processes of cell maturation and division. Studies on the mineral nutrition of a Selenastrum were described by K. V. Natarajan. In a lecture on the extracellular products of algae, G. E. Fogg presented evidence showing that the liberation of these is widespread and that enzymes are included among the very varied kinds of substances involved. These extracellular substances may be of ecological importance in various ways, as, for example, by forming chemical complexes with inorganic ions. The kinetics of the production of extracellular nitrogenous substances by a nitrogen-fixing Nostoc isolated from the root nodules of Trifolium alexandrinum was discussed by G. S. Venkataraman. In another paper on nitrogen fixation, G. E. Fogg emphasized the close intermeshing of this process with photosynthesis which occurs in blue-green algae. He also reported nitrogen fixation by Chlorogloea fritschii, evidently the first unicellular member of the group in which this property has been 